\section{¿GENTRIFICACIÓN EN ZONAS PATRIMONIALES? ESTUDIO DE CINCO CASOS EN SANTIAGO DE CHILE ${ }^{1}$}

Marco Antonio Valencia Palacios ${ }^{2}$

\section{Resumen}

El presente artículo se pregunta por los efectos que un conjunto de barrios tradicionales de ubicación pericéntrica del Gran Santiago ha tenido producto de su reciente reconocimiento como Zona Típica y Pintoresca, figura legal contenida en la Ley de Monumentos Nacionales (Ley MINEDUC, 17.288), cuyo fin es salvaguardar áreas que presentan valores históricos, estéticos y arquitectónicos. Específicamente se busca reconocer si los sectores declarados han sufrido procesos de deterioro o valorización. Para ello, se utiliza un conjunto de herramientas de producción de información que permiten evaluar la condición de las zonas en un conjunto de dimensiones. Se considera la opinión

\section{GENTRIFICATION IN HERITAGE AREAS? A STUDY OF FIVE CASES IN SANTIAGO, CHILE'}

Marco Antonio Valencia Palacios ${ }^{2}$

\section{Abstract}

This paper questions the effects experienced by traditional neighborhoods located in the peri-urban area of Greater Santiago as the result of their recognition as Traditional and Scenic Area-as laid out in the National Monuments Act [MINEDUC Act 17,288], which is intended to preserve the historical, aesthetic and architectural features of specific areas. This work specifically seeks to identify if these neighborhoods have undergone processes of deterioration or valuation. To this end different tools of information production are used in order to evaluate the condition of these areas from different perspectives. This research gathers opinions from heritage activists and local inhabitants and analyzes 
de informantes calificados de perfil activista patrimonial y vecinos de los barrios estudiados. A su vez, se analizan los resultados obtenidos de una encuesta a una muestra representativa de residentes de las cinco zonas típicas estudiadas. Por último, se desarrolla un análisis del comportamiento de los precios de la oferta de inmuebles al interior y en el borde de los barrios estudiados, con el fin de reconocer un posible proceso de gentrificación.

PALABRAS CLAVE: DETERIORO; VALORIZACIÓN; ÁREAS PATRIMONIALES; GENTRIFICACIÓN

Recibido: 09-07-2018

Aceptado: 21-03-2019 the results of survey of a representative sample of residents from the five typical areas under review. Lastly, it examines the evolution of property prices within and around these areas to identify a possible gentrification process.

\section{KEYWORDS: DETERIORATION; VALUATION; HERITAGE AREAS; GENTRIFICATION}

Received: 09-07-2018

Accepted:21-03-2019
Fondecyt Iniciación n ${ }^{\text {ro }} .11150218$ de Conicyt 2015.

2 Chile. Centro de Estudios Arquitectónicos, Urbanos y del Paisaje de la Universidad Central de Chile, https://orcid.org/0000-00025675-0981. Correo electrónico: mvalenciap@ucentral.cl.
1 Fondecyt Iniciacion project 11150218, Conicyt, 2015.

2 Chile. Center for Architectural, Urban and Landscape Studies, Universidad Central de Chile, https://orcid.org/0000-00025675-0981. Email: mvalenciap@ucentral.cl. 


\section{Introducción}

Se ha señalado que las aplicaciones de políticas neoliberales en las ciudades han sufrido un constante cuestionamiento, generando diversas formas de resistencia a los programas de reestructuración urbanas emanados de ella (Brenner, Peck y Theodore, 2009).

Para Harvey, la reproducción del capital pasa por los procesos de urbanización por múltiples vías: controlando los aparatos de Estado que administran y gobiernan las condiciones sociales y la infraestructura dentro del territorio y también controlando la totalidad de la población: "su forma de vida, así como su capacidad de trabajo, sus valores culturales y políticos así como sus concepciones de mundo" (Harvey, 2012). Ese nivel de control no se logra fácilmente, por lo que la ciudad y los procesos urbanos que produce son importantes foco de lucha política, social y de clase. Es así que, frente a la acumulación por despojo en las zonas urbanas empobrecidas y de clases medias, donde alguna vez operó el Estado de bienestar, y que hoy sufren cambios bajo la forma de privatizaciones y mercantilización de las relaciones sociales, la ciudadanía organizada ha desarrollado diversas formas de resistencia. Desde las comunidades urbanas organizadas en torno a lo vecinal, pasando por movimientos ambientalistas e indigenistas, las sociedades se han organizado frente a las amenazas que las reestructuraciones del sistema neoliberal han generado sobre sus territorios y modos de vida (Zibechi, 2015).

Para el caso chileno se ha señalado que, desde la década de 2000, conflictos vinculados a la construcción de proyectos urbanos en barrios tradicionales gatillaron la formación de organizaciones ciudadanas que asumen una oposición a dichos proyectos modernizadores (Ducci, 2004). Dentro de las estrategias utilizadas por las comunidades, desde fines de la década pasada ha estado el recurrir a la solicitud de declaratoria de Zona Típica y Pintoresca ${ }^{3}$ como resistencia a diversas amenazas modernizadoras (Valencia, 2016 y 2017), "para luego abrir un horizonte de acción en torno a la difusión y recuperación del patrimonio tangible e intangible presente en los barrios" (Rojas, 2015). Tanto en la fase de amenaza y de conflicto, como la de reacción-resistencia y luego en la gestión y sustentabilidad de las áreas declaradas, se presenta una gama variada de actores sociales involucrados.

3 Se refiere a la protección de conjuntos urbanos o rurales, entornos de monumento histórico, áreas con valor histórico, artístico, ambiental como calles, plazas; que presentan valores estéticos, arquitectónicos o históricos y que, al distinguirse por su unidad y singularidad, representan un conjunto de valores de una determinada época. 
El presente artículo pretende identificar las diversas visiones que tienen los activistas patrimoniales y vecinos, respecto del creciente proceso de patrimonialización de cinco barrios del Gran Santiago: Matta Sur y Yungay, en la comuna de Santiago y Villa Frei, Empart Salvador y Villa Olímpica en la comuna de Nuñoa. El objetivo principal es analizar si dicho proceso patrimonializador ha significado deterioro o valoración de los barrios mencionados. En especial se busca reconocer la posible presencia de procesos de gentrificación en los barrios estudiados. Para ello, primeramente, el texto despliega una breve descripción conceptual del concepto de gentrificación, identificando sus usos y definiciones más frecuentemente utilizados por la literatura latinoamericana.

En segundo lugar, se analiza la información procedente de la aplicación de entrevistas semiestructuradas realizadas a activistas patrimoniales y vecinos de los cinco sectores mencionados. A continuación, se presentan los resultados del estudio de la dinámica de la oferta del mercado habitacional, en el interior de las zonas típicas y en las áreas inmediatamente circundantes, en un rango de tiempo anterior y posterior a la declaratoria de zona típica. El rango del estudio longitudinal (cinco años) se encuentra determinado porque varios de los barrios estudiados han sido declarados patrimoniales recientemente.
Finalmente, se presenta parte de los resultados de una encuesta a una muestra representativa de vecinos de las zonas típicas mencionadas, que aborda las dimensiones relacionadas con la percepción general del barrio y del proceso de patrimonialización. A partir de la información obtenida por la aplicación de las metodologías descritas, el artículo indaga acerca de la presencia de posibles procesos de gentrificación en los casos estudiados. Se concluye que, si bien hay una re-valorización de los barrios, por lo menos en el corto plazo, no es posible reconocer indicadores que den cuenta de un proceso clásico de gentrificación. Sin embargo, en algunos de los casos estudiados es posible identificar algunos atributos característicos de procesos de gentrificación propios de barrios centrales latinoamericanos (Delgadillo, 2015; Navarrete, 2017).

\section{Aproximaciones al concepto de gentrificación}

El término gentrification fue acuñado por la socióloga Ruth Glass al observar cómo en áreas centrales de ciudades inglesas se estaba generando un proceso de desplazamiento de residentes de clases bajas por la llegada de la gentry, es decir, de la clase alta; estas áreas con buena localización y construcciones deterioradas son retomados por 
una clase burguesa joven que aprovecha los precios bajos (Glass, 1964). Es así como en adelante cierta literatura ha vinculado el concepto de gentrificación con el proceso de desplazamiento de un tipo de población de bajos ingresos por una de ingresos altos. Se han establecido tres fases sucesivas en dicho fenómeno: un primer momento de abandono de clases medias y altas del sector; un segundo momento de repoblamiento de clases populares; y un tercer momento de revitalización económica, cuando se produce la sustitución de sectores sociales (Deutsche, 1996; Pacione, 1990; Slater, 2015; Smith, 2012).

En la literatura anglosajona es posible reconocer un primer momento de desarrollo de proceso gentrificador en el inicio de la segunda mitad del siglo $\mathrm{XX}$, asociada con las contracciones del crecimiento de la economía en el marco del Estado benefactor y su impacto en las economías de escala de los territorios, en particular en los barrios obreros pauperizados de Europa Occidental y EE.UU. Este proceso ha sido caracterizado como ciclo de gentrificación esporádica. Una segunda oleada da cuenta de un fenómeno más amplio, caracterizado como de ampliación y responde al impacto de los nuevos patrones mercantiles de liberalización del suelo urbano y la imposición de criterios de consumo y gustos asociados al capital cultural y a la localización de segmentos de población económicamente emergentes. El último y más reciente, que data de la década de 1990, tiene un carácter global. En estos casos, la rápida valorización del suelo, junto con el deterioro de los activos y procesos de desregulación asociados a políticas de corte neoliberal detonan el desplazamiento de la población de escasos recursos, cuyos bienes depreciados son adquiridos por grupos con mayores recursos económicos (Inzulza y Galleguillos, 2014; Lees, Slater y Wyli, 2008). Sus formas de expresión sociológica y geográfica no siguen un patrón de comportamiento homogéneo, presentando variadas expresiones de los cambios físicos en los territorios, según se ponga el acento en el aspecto espacial, cultural o económico (Janoschka, Sequera y Salinas, 2014; Lees et al., 2008).

Como sea, en todos los períodos históricos el elemento que ha caracterizado estructuralmente el proceso es el incremento de precios de suelo, la llegada de población de mayores ingresos (en diversa magnitud) a sectores depreciados y la reprogramación de servicios y equipamientos para turismo y/o sectores de altos ingresos. Del mismo modo, parece generar consenso entre los autores, una explicación del fenómeno basado en la teoría de la diferencia potencial de la renta o rent gap, que define la diferencia entre una renta actual y potencial de un terreno como factor detonante y explicativo de un proceso de gentrificación (Smith, 2012). De este modo, se da un uso más lucrativo al suelo poniendo en peligro el activo que, deteriorado pierde 
valor en el mercado. Para Neil Smith, este proceso de oferta de espacio gentrificable se da en un espacio de tiempo acotado, inicialmente en sectores centrales donde los activos inmobiliarios son más valiosos por su escasez.

Ahora bien, este proceso de captura de renta potencial puede o no ir asociado de procesos de expulsión significativos, como se ha discutido en literatura reciente, sobre todo en Latinoamérica (Delgadillo, 2015; Janoschka et al., 2014; Sabatini, Vásquez, Robles y Rasse, 2010). Ahora, bien la gentrificación no solo ha sido entendida como el proceso de sucesión y reemplazo voluntario e involuntario de una clase de ingresos bajos por una de ingresos altos. También, ha sido entendida como un proceso que genera cambios en los usos de suelo, ya sean residenciales, culturales, educacionales o comerciales. Para el caso de los barrios patrimoniales, en general, se plantea un cambio, no tanto de habitantes originales en los sectores patrimonializados, pero sí de usos y funciones de residencias con fines turísticos y de servicios exclusivos (Navarrete, 2017). En este caso el fenómeno difiere del patrón clásico de los países del norte y se caracteriza por una gentrificación sin expulsión y por un cambio en las actividades productivas de servicios y comercio tradicionales y de proximidad por servicios con vocación internacional, principalmente en actividades de turismo cultural (Navarrete, 2017). El caso de la llegada de galerías de arte a barrios obreros desfavorecidos ha sido ampliamente relatado por la literatura anglosajona (Deutsche y Gendel, 2015; Smith, 2012). La seducción de áreas centrales por su oferta cultural para con los profesionales jóvenes, llevó a fines del siglo XX, a planteamientos como el de la existencia de una nueva "clase creativa", considerada como el principal agente gentrificador de barrios empobrecidos (Florida, 2002). Actualmente, nuevos fenómenos han especificado los impactos gentrificadores de cambios de uso y programación en barrios centrales: la llamada boutiquización, proliferación de tiendas y marcas de ropa exclusiva en reemplazo de viviendas para pobres y pequeño comercio a escala barrial o la turistificación, de sectores patrimoniales, definida como la masiva concentración de servicios turísticos que genera un fenómeno descontrolado de alquileres desregulados, que sobrepasa la capacidad de carga de los lugares históricos (Delgadillo, 2015; Navarrete, 2017; Vergara y Casells, 2016).

Para el caso latinoamericano el fenómeno se sitúa a fines de la década de 1990 (Delgadillo, 2015; Inzulza, 2014), de la mano de políticas de reestructuración económica de corte neoliberal, al generar políticas de desregulación y flexibilización de los mercados de suelo. Su efecto sería perceptible tanto en áreas centrales (Contreras, 2016; López, Gasic y Meza, 2012; Urbina, 2015; Vergara y Casells, 2016), pericéntricas (Inzulza y Galleguillos, 2014) 
y periféricas (Sabatini et al., 2010). Sin embargo, los atributos que permiten definir conceptualmente el fenómeno varían desde visones que se centran en la generación de potencial de renta o en cambios en usos de suelo y reprogramación en los sectores. Para Delgadillo los efectos de la revalorización de barrios históricos en Latinoamérica son multidimensionales y abarcan aspectos inmobiliarios, físicos, socio-económicos y culturales.

En términos generales, para el caso latinoamericano la gentrificación cobra fuerza en las últimas décadas debido a las reformas de liberalización del mercado de suelo de fines de siglo XX, que fomentan el aumento de la inversión privada en el negocio inmobiliario. Las ciudades quitan restricciones al suelo generando un ambiente propicio para la llegada de capitales a los territorios, aumentando significativamente la producción masiva de viviendas (López et al., 2012). Los sistemas de subsidios estatales a la demanda y las modificaciones de los Planes Reguladores Comunales (PRC), instrumento normativo que regula el ordenamiento territorial en la escala local, son ilustrativos para el caso chileno. La tardía recepción del concepto para hacerlo operativo en casos latinoamericanos se explicaría por la escasa evidencia empírica de una invasión seguida por una expulsión de habitantes en corto tiempo (Sabatini et al., 2010; Urbina, 2015). Es así como estudios recientes han demostrado que los procesos gentrificadores en cascos históricos latinoamericanos se caracterizan por una llegada escasa de nuevos residentes y una fuerte presencia de inmigrantes nacionales de bajos ingresos. Del mismo modo se plantea la coexistencia de una oferta de servicios para sectores de mayores ingresos con equipamientos destinados a los sectores populares y medios (Delgadillo, 2015; Hiernaux y González, 2014). En la misma línea Sabatini et al. (2010) sostienen que, si bien no ha sido demostrada la expulsión de residentes seguida del proceso de captura de potencial de renta, no es descartable que en el mediano plazo los procesos especulativos pudiesen generar desalojos. Para definir gentrificación en la especificidad latinoamericana, se planten dos características principales que definen el proceso. Por una parte, la llegada de grupos de mayor capacidad económica que la población residente y el incremento generalizado y rápido de los precios del suelo en un contexto de deterioro físico de las estructuras, es decir la generación del potencial de renta. Siguiendo estos parámetros varios autores de la región reconocen la existencia de procesos de gentrificación en los casos estudiados. Para el caso de áreas centrales en la capital de Chile, Contreras reconoce para algunos barrios del centro de Santiago, un aumento sucesivo de los valores de suelo en áreas deterioradas, donde se instala el plan de repoblamiento llamado Programa de Renovación Urbana; a su vez se reconoce la llegada de población de mayores o iguales ingresos que la población residente en dichas áreas. 
Aunque este perfil de advenedizo no es exclusivo, ya que la llegada de población migrante latinoamericana de bajos recursos es significativa (Contreras, 2016). Para otros especialistas la expresión latinoamericana de la gentrificación se caracteriza por un conjunto de trasformaciones respecto del modo de habitar, que de la mano de nuevos patrones estructurales del mercado habitacional, se expresan en una mayor presencia de densificación en altura y condominios, espacios que generan polarización y segregación en los territorios, marcados por el individualismo, y la distinción cultural asociada al consumo de bienes simbólicos y materiales, que se ve expresada en la instalación de nueva infraestructura cultural y de ocio para sectores de mayores ingresos (Inzulza y Galleguillos, 2014). En este sentido, para Delgadillo, los procesos de boutiquización, parquetematización y turistificación de barrios históricos es considerada un efecto nocivo para la sustentabilidad del patrimonio urbano (Delgadillo, 2015; Navarrete, 2017).

Para el caso específico de un centro patrimonial, el centro histórico de Bogotá, los especialistas asumen que pasa por un proceso de gentrificación con características particulares. El uso de la norma, al permitir la intervención interior de ciertos inmuebles, favorece cambios de uso y modificaciones interiores que han hecho que las estructuras vean afectadas su integridad física, aumentando su estado de deterioro ${ }^{4}$. A su vez, la llegada de centros educacionales privados, ha aumentado el alquiler de bajo costo, generando modificación y alteraciones en edificaciones patrimoniales (Urbina, 2015). Este fenómeno genera una desvalorización de los terrenos del área central, posibilitando un efecto de compra para capturar el potencial de renta. Esta hipótesis considera que la patrimonialización, bajo determinadas condiciones normativas, genera deterioro, el que, sin embargo, es potencialmente rentabilizado para renovación.

En ambos casos, Bogotá y Santiago de Chile, se reconoce la coexistencia de clases bajas y altas en el área central. Para el primer caso, haciendo referencia específica a dos barrios, se plantea una cierta complejización en la estructura social con una disminución de las dos clases más bajas, una concentración de población de escasos recursos en sectores puntuales, una permanencia de la clase más alta y un leve crecimiento de las clases intermedias (Dureau, Barbary y Lulle, 2007). Para el caso de centro histórico de Santiago se ha definido una mixtura socio-espacial, donde coexisten situaciones de segregación, relegación, expulsión, densificación, renovación, reciclaje y tugurización (Contreras, 2016). Para Inzulza y Galleguillos (2014), el proceso de gentrificación en el centro de Santiago se caracteriza por la sustitución de edificación preexistente de fachada continua o pareada, de uno

4 Según Urbina (2015), el 55\% de las edificaciones presenta deterioro. 
o dos pisos, originalmente de uso residencial, por una tendencia de residencia con vivienda en media-altura y altura, "más que al desplazamiento de clases obreras, o de menores ingresos".

Ahora bien, el desplazamiento de población residente como atributo medible y verificable en zonas patrimonializadas, no ha sido demostrado como un fenómeno masivo en las áreas centrales e históricas de las ciudades de nuestra región. En el caso de Santiago de Chile, autores coinciden en que ha habido grados diversos de expulsión de habitantes en algunas zonas del centro de la capital, sujetas a políticas de repoblamiento y renovación (Contreras, 2016; López et al., 2012). Sin embargo, el proceso de patrimonialización no ha sido considerado un atributo que, hasta ahora, explique la expulsión de población. Sin embargo, López et al. plantean que, para el caso del peri-centro de la comuna de Santiago, los procesos de desplazamiento de población son de largo plazo y los desplazados pertenecen a un sector invisibilizado, por lo que los proceso pueden ser evidentes con posterioridad. Valparaíso, de la mano de una política patrimonial de inspiración global (UNESCO) presenta para algunos autores antecedentes que permiten caracterizar un proceso de gentrificación con expulsión no masiva de población y cambios en la estructura de usos y programación de barrios tradicionales en algunos cerros específicos (Navarrete, 2017; Sobarzo, 2009; Vergara y Casells, 2016). Para el caso de ciudades mexicanas, se han reconocido políticas estatales y locales de desplazamiento de comercio informal o de población en situación de calle de los espacios públicos de áreas patrimonializadas (Duering, González e Hiernaux, 2016).

\section{Metodología}

Se realiza una breve sistematización bibliográfica de la literatura reciente respecto de la definición y aplicación del concepto de gentrificación en los países occidentales, en particular en Latinoamérica.

Se realiza un estudio del comportamiento del mercado habitacional en cinco zonas típicas, considerando los promedios de oferta de precio de venta y arriendo de departamentos dentro de las zonas protegidas y las áreas inmediatamente colindantes, durante cinco años, dos años antes y dos años después de la declaratoria. Se estima como dato general el comportamiento de la curva de valores promedio de $\mathrm{m}^{2}$ comunal, en los mismos años en que se miden los predios de venta/arriendo departamentos en la zona típica. La curva de valores, 
obtenida de Trivelli ${ }^{5}$, permite una referencia general respecto del comportamiento de los valores de $\mathrm{m}^{2}$ comunal considerando una muestra aleatoria de casos, que incluyen no solo lotes residenciales.

Se realiza una encuesta a una muestra representativa $^{6}$ de residentes de las cinco zonas típicas estudiadas, correspondientes a los territorios definidos por los polígonos que establecen los límites de las declaratorias de zonas típicas de los barrios Villa Frei, Empart Salvador y Villa Olímpica en la comuna de Nuñoa; y Barrio Yungay y Barrio Matta Sur en la comuna de Santiago (Figura 1). La población considerada en el estudio corresponde a hogares que residen al interior de estos polígonos de protección. Las dimensiones consideradas en el estudio dicen relación con una caracterización general de los habitantes y su percepción general respecto del barrio y de los efectos del proceso de patrimonialización.

Se considera a su vez la opinión de informantes calificados de perfil activista patrimonial y vecinos

5 La curva de valores, obtenida del Boletín Trimestral de Precios de Suelo (Trivelli, 2017), permite una referencia general respecto del comportamiento de los valores de $\mathrm{m}^{2}$ comunal considerando una muestra aleatoria de casos, en que se calcula promedio cantidad de ofertas, metros ofertados y precio del $\mathrm{m}^{2}$.

6 El diseño maestral corresponde a un modelo estratificado con fijación proporcional y consideró un total de 218 hogares encuestados.

\section{FIGURA 1. PLANO LOCALIZACIÓN DE ZONAS TÍPICAS CONSIDERADAS EN EL ESTUDIO.}

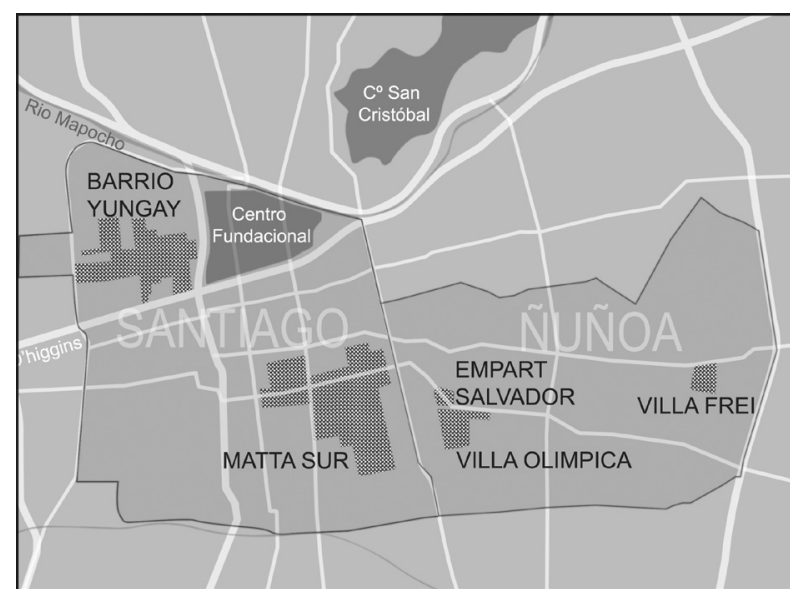

Fuente: elaboración propia.

de los barrios estudiados, mediante aplicación y sistematización de entrevista semi-estructurada, procesada a través de la técnica de análisis de discurso. 


\section{¿Se gentrifican las recientes zonas típicas?}

Teniendo como antecedente las referencias conceptuales citadas, se intentará responder si es posible relacionar los procesos de patrimonialización reciente de barrios tradicionales de ubicación pericéntrica en Santiago de Chile, con indicadores atribuibles a un proceso gentrificador en dichos sectores.

En término generales, ha existido una percepción negativa del sector privado inmobiliario chileno respecto de la política patrimonial del Estado (Irarrázaval, 2017). Para los privados la duplicidad normativa, la falta incentivos financieros a los propietarios de inmuebles y una dispersión de los organismos públicos encargados del tema patrimonial, generan un terreno complejo para la inversión privada. Esto redunda, en términos generales, en un deterioro de inmuebles y zonas patrimonializadas. Sin embargo, esta percepción se matiza cuando se analizan las recientes declaratorias de zonas típicas. Reconocen un aumento creciente del fenómeno. Esto lo atribuyen a políticas reactivas por parte de comunidades que ven amenazados sus entornos barriales tradicionales por los desarrollos habitacionales densificados en altura. En cuanto al impacto, lo reconocen como heterogéneo. Por un lado, existe la visión de que la zona típica, al restringir los procesos de edificación, frena la inversión privada, y esto, junto al escaso financiamiento estatal, termina por generar abandono y deterioro de los inmuebles y del sector. Sin embargo, también se señala que la aplicación de normativas restrictivas en barrios reconocidos y con localización privilegiada, al disminuir los coeficientes de constructibilidad, genera un aumento del valor de suelo.

Por su parte, la percepción tanto de vecinos como de activistas patrimoniales indica que ha habido una mejoría relativa en los barrios, atribuible a intervenciones diversas, tales como activación de espacios públicos, mejoras en fachadas, mejoramiento de espacios públicos y áreas verdes, vialidad o equipamiento. Estos procesos cuentan con diversos financiamientos, no siempre asociados al reconocimiento patrimonial. Como sea, lo que se puede aseverar es que la recurrente afirmación respecto de que la declaratoria patrimonial suele tener como consecuencia un deterioro de los inmuebles y del sector, no es algo que pueda afirmarse para estos casos.

Por el contrario, esta hipótesis del deterioro y desvalorización de los sectores patrimonializados queda aún más en entredicho cuando revisamos otros factores que permiten sostener más bien un proceso de renovación en algunos aspectos y en diversos grados en estos barrios.

Como se ha dicho, una hipótesis general que los actores sociales, en particular el sector inmobiliario 
y los propietarios de inmuebles patrimoniales, es que uno de los efectos de la protección legal de áreas urbanas es un estancamiento del mercado inmobiliario.

Un estudio reciente ha intentado mensurar el comportamiento del mercado inmobiliario mediante el estudio de la variación de precio del suelo, comparando datos de construcción y transacción de inmuebles y suelo en zonas típicas, con otras áreas de la ciudad (Jeri, 2015). La autora emplea los datos del Boletín Trimestral de Precios de Suelo (Trivelli, 2017) para comparar las dinámicas inmobiliarias dentro de la zona declarada con el promedio comunal. Para el caso del barrio Yungay, los resultados indican un incremento del valor de los predios, que coincide con el alza relativa de valores de la comuna de Santiago. Sin embargo, "al analizar las tasas con que van cambiando estos valores, se observa que, en este barrio, las tasas de crecimiento inter-trimestrales han aumentado más significativamente después de la declaratoria, dentro del barrio, que, en la comuna, donde se produce un enlentecimiento de la tasa de crecimiento trimestral de valor $\mathrm{UF} / \mathrm{m}^{2 "}$ (Jeri, 2015). Respecto a la oferta de terrenos el estudio reconoce que esta ha ido disminuyendo progresivamente, al igual que el promedio comunal, pero más lentamente. Y en cuanto al dinamismo del mercado, la cantidad de ofertas promedio decrece luego de la declaratoria de zona típica, al igual que en el total comunal. Esto dice relación con la disminución de paños urbanizables, producto del fin del ciclo de dinamismo asociado al plan de repoblamiento, a la modificación del PRC y a la propia declaratoria de zona típica. Finalmente, el estudio concluye que la declaratoria parece haber afectado muy levemente la dinámica de oferta predial, puesto que se verifican cambios en direcciones similares a los de la comuna de Santiago. Sin embargo, se observa un aceleramiento de mayor envergadura relativa dentro del barrio en comparación a la experimentada en la comuna.

Estos datos generales respecto de los valores de suelo reafirman la argumentación en cuanto a que no existe una desvalorización del sector, sino una contracción de la dinámica inmobiliaria y un aceleramiento posterior a la declaratoria. En términos teóricos esta disminución de la oferta, asociada a la disminución del stock y a las restricciones normativas, explicaría un incremento potencial de los valores de suelo en la zona.

A partir de esta tendencia general, observada en Yungay, cabe preguntarse respecto a sí es posible reconocer grados de gentrificación significativos en cinco zonas típicas recientemente declaradas. Conceptualmente la gentrificación ha sido definida como un fenómeno de recambio de población de estratos bajos por medios y altos en barrios tradicionales que presentan algún grado de deterioro de su stock residencial, que genera cambios de uso y reprogramación cultural y de ocio excluyentes. Para responder la pregunta respecto de la 
valorización y posible gentrificación, se buscarán reconocer la presencia o ausencia de los siguientes atributos después de la declaratoria: comportamiento del mercado habitacional al alza, arribo de nuevos habitantes con mayor poder adquisitivo, presencia de nuevos programas culturales y de ocio y desplazamiento de población vulnerable.

\section{Comportamiento del mercado habitacional. Precios de venta $y$ arriendo de inmuebles antes y después de la declaratoria}

Se realizó un estudio longitudinal de precios de inmuebles en barrios declarados zona típica. En particular, se intentó medir el comportamiento de mercado inmobiliario, a través del promedio de precios de oferta de arriendo y venta de departamentos, por tratarse de una unidad habitacional presente en los cinco sectores estudiados y por constituirse en la preferencia residencial mayoritaria de los santiaguinos. Esto permite además aislar posibles usos no residenciales que suelen darse en la tipología residencial, casa. Los casos seleccionados corresponden a arriendo y venta de departamentos en períodos anuales antes y después de la declaratoria, obtenidos de avisos de oferta en portales de internet y diarios de circulación nacional ${ }^{7}$.

Al revisar los datos respecto a Empart-Salvador (Figura 2), declarado zona típica el año 2010, se percibe un aumento significativo de los precios de arriendo de departamentos, desde 2011. Con anterioridad a la declaratoria, se aprecia una contracción atribuible a la crisis económica de 2008. De todas formas, esta alza importante de los valores de arriendo sigue, en términos generales, el movimiento de la curva de valores de suelo de la comuna de Nuñoa, lo que permite asegurar en primer término, que las áreas declaradas no presentan una tendencia a desvalorizarse respecto de la comuna, y segundo, que no es posible discriminar a la declaratoria de zona típica, como un factor determinante en el alza de precios.

Para el caso de Villa Frei (Figura 3), declarada zona típica en 2015, los datos de oferta de venta de departamentos arrojan, al igual que en los arriendos de Empart, un alza significativa del precio a un año después de la declaratoria (2016) y luego 2017, en alzas superiores al 20\%. El promedio de precios de arriendos, si bien sube, en 2016, más levemente que el promedio de venta, cae en los datos obtenidos para 2017. Esto hablaría de una contracción del proceso especulativo general respecto de la valoración de esos inmuebles, toda vez que el ciclo 
FIGURA 2. GRÁFICO OFERTA DE ARRIENDOS EN LA ZONA TÍPICA EMPART.

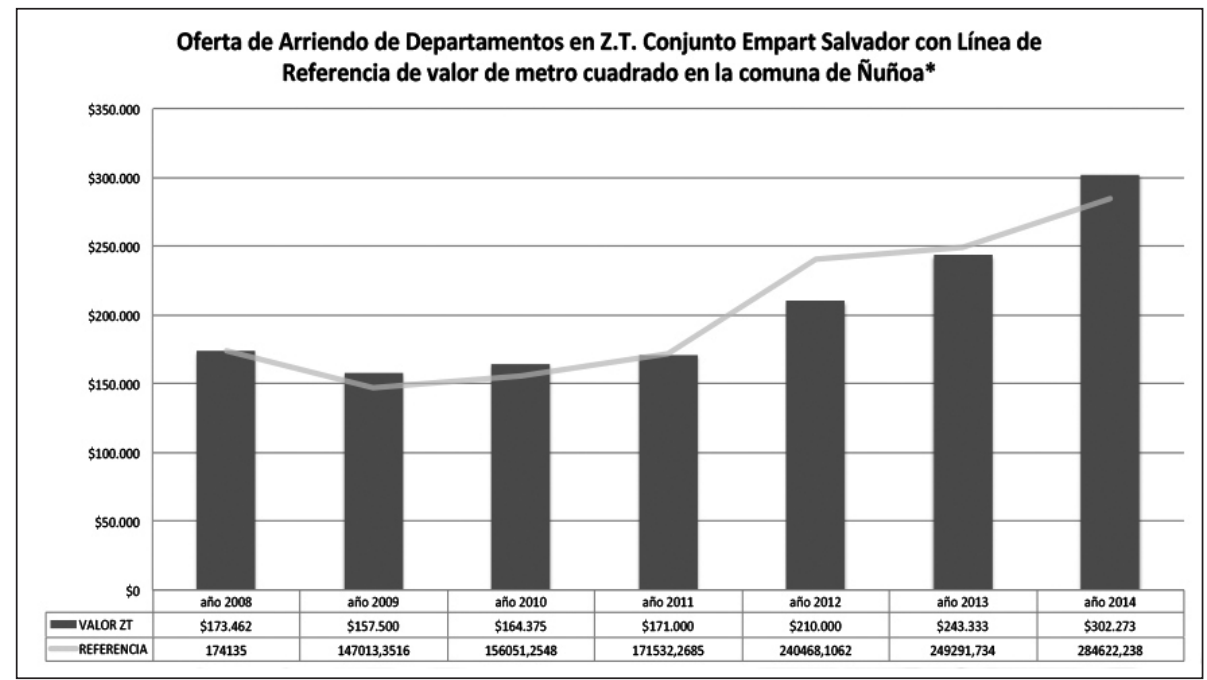

Fuente: elaboración propia.

FIGURA 3. GRÁFICOS OFERTA DE ARRIENDOS Y VENTA DE DEPARTAMENTOS EN LA VILLA FREI.

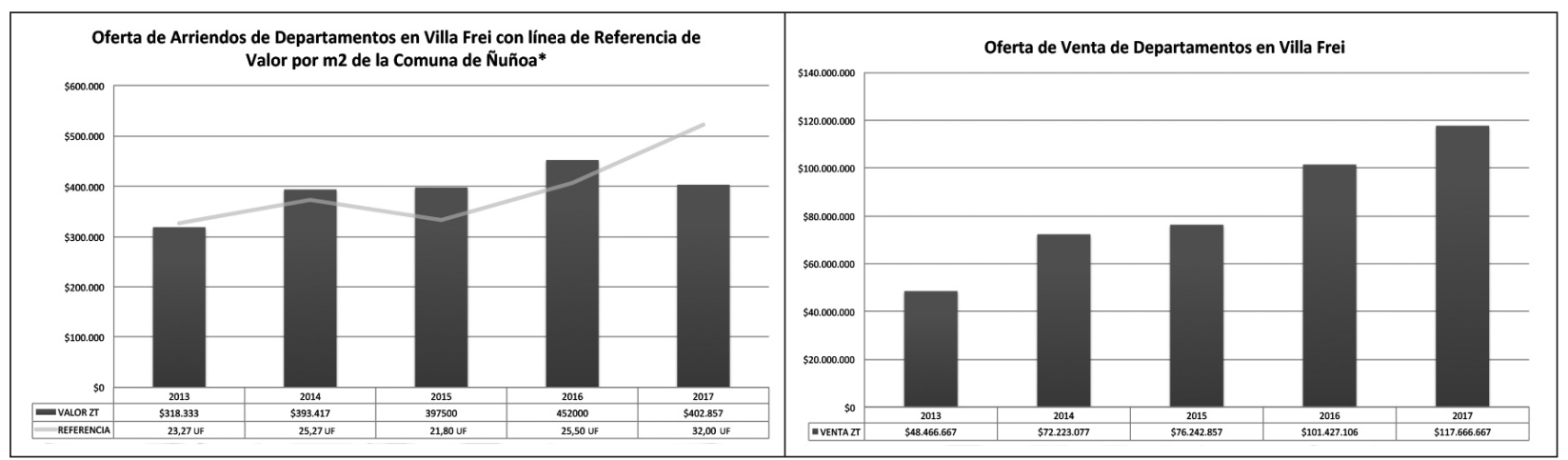

Fuente: elaboración propia. 
especulativo del precio de oferta de arriendo suele ser más corto que el de venta. Habría que esperar en el mediano plazo una contracción del precio de venta de departamentos, que para 2017, bordean en promedio los $\mathrm{M} \$ 120.000$, aumentando su valor tres veces desde 2011. ¿Es posible atribuir como un factor contribuyente a este ciclo especulativo en alza la declaratoria de zona típica? La construcción de la estación de metro Villa Frei, anunciada en 2013, cuyas obras se iniciaron en 2014 e impulsaron la organización patrimonial, sin duda ha sido un factor determinante en el alza generalizada de los valores de suelo del sector, no obstante, hay alzas significativas tanto después del anuncio de la llegada del metro, como después de la declaratoria.

Para el caso de Villa Olímpica (Figura 4), declarada zona típica en 2016, es posible apreciar un alza significativa continua del precio promedio de venta de departamentos desde antes de la declaratoria (2014), hecho atribuible al alza general del valor de suelo comunal (como lo indica la curva promedio de precio $\mathrm{m}^{2}$ comuna Nuñoa), a la llegada de la estación de metro Estadio Nacional (se inaugura en 2017) y a las obras de reconstrucción. Ahora bien, el proceso de patrimonialización en la Villa, en cuanto difusión e instalación en la opinión pública, se inicia paralelamente con el tema de la reconstrucción, siendo un argumento central para impedir la demolición de los bloques dañados por el terremoto. De hecho, el proyecto Fondart para la elaboración del expediente data de 2011. En este caso la patrimonialización es un fenómeno paralelo al de la valorización general el conjunto, que se explica multifactorialmente.

En el barrio Yungay, declarado zona patrimonial el año 2009, se reconoce un alza de los valores promedio de arriendo de departamentos, desde dos años después de la declaratoria. Se aprecia una contracción para el período 2008-2010, atribuible a la crisis económica y al terremoto de 2010. Desde 2011 a 2013 se observa un alza sostenida. Como se aprecia en el Figura 5, si se compara el buffer ${ }^{8}$ con el polígono de la zona típica, a fin de aislar la variable de protección legal de la zona respecto al sector colindante no protegido. Se concluye un comportamiento similar del precio promedio de oferta de arriendo de departamentos en ambas áreas. Ello permite afirmar, por una parte, que no hay una desvalorización general de los inmuebles del área declarada zona típica respecto de los valores generales del sector, y que la variable patrimonialización no reporta un comportamiento al alza de valores de arriendo respecto del área colindante. Del mismo modo, al superponer la tendencia de la

8 El buffer se define como el conjunto de manzanas inmediatamente colindantes con el borde al polígono de la declaratoria de zona típica, y se consideran, al igual que en la zona típica, valores de oferta de arriendos de departamentos. 


\section{FIGURA 4. GRÁFICOS OFERTA DE ARRIENDOS Y VENTA DE DEPARTAMENTOS EN LA VILLA OLÍMPICA.}

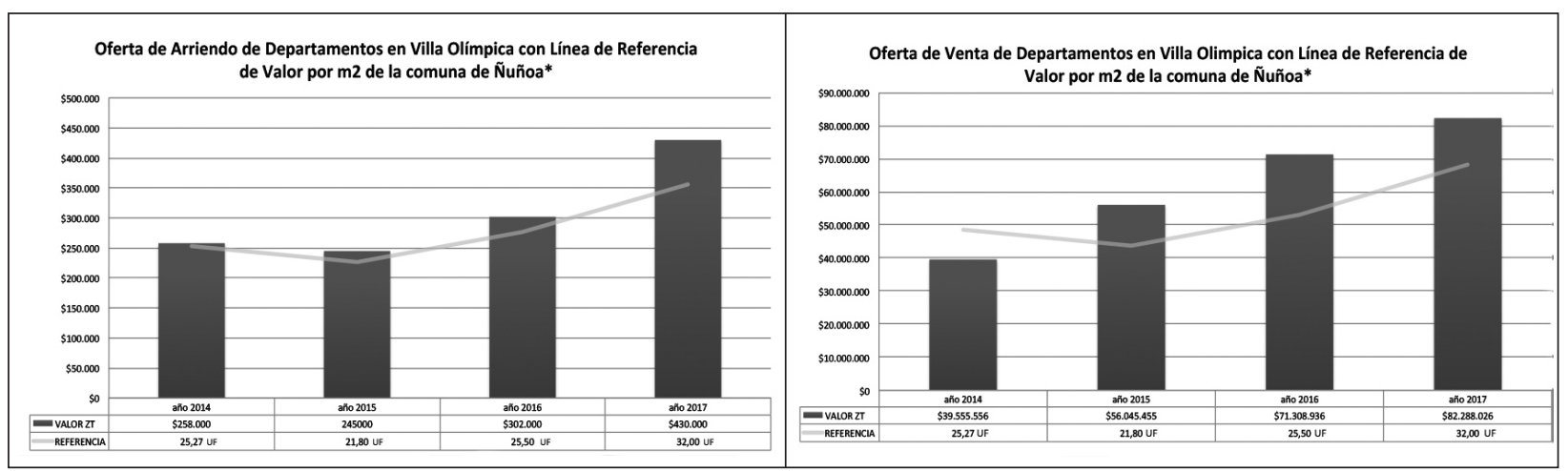

Fuente: elaboración propia.

\section{FIGURA 5. GRÁFICOS DE OFERTA DE ARRIENDOS EN YUNGAY Y BUFFER Y OFERTA DE ARRIENDO DE DEPARTAMENTOS EN YUNGAY.}

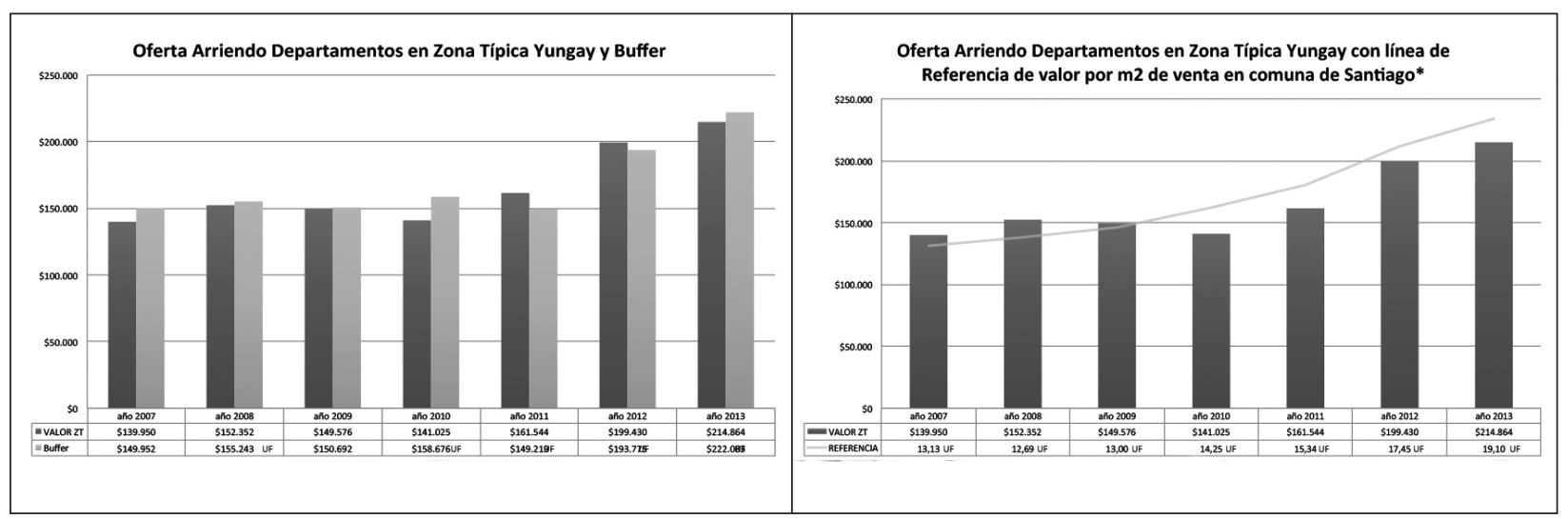

Fuente: Elaboración propia. 


\section{FIGURA 6. GRÁFICOS DE OFERTA DE ARRIENDOS EN MATTA SUR Y REFERENCIA DEL VALOR DE M2 EN SANTIAGO.}

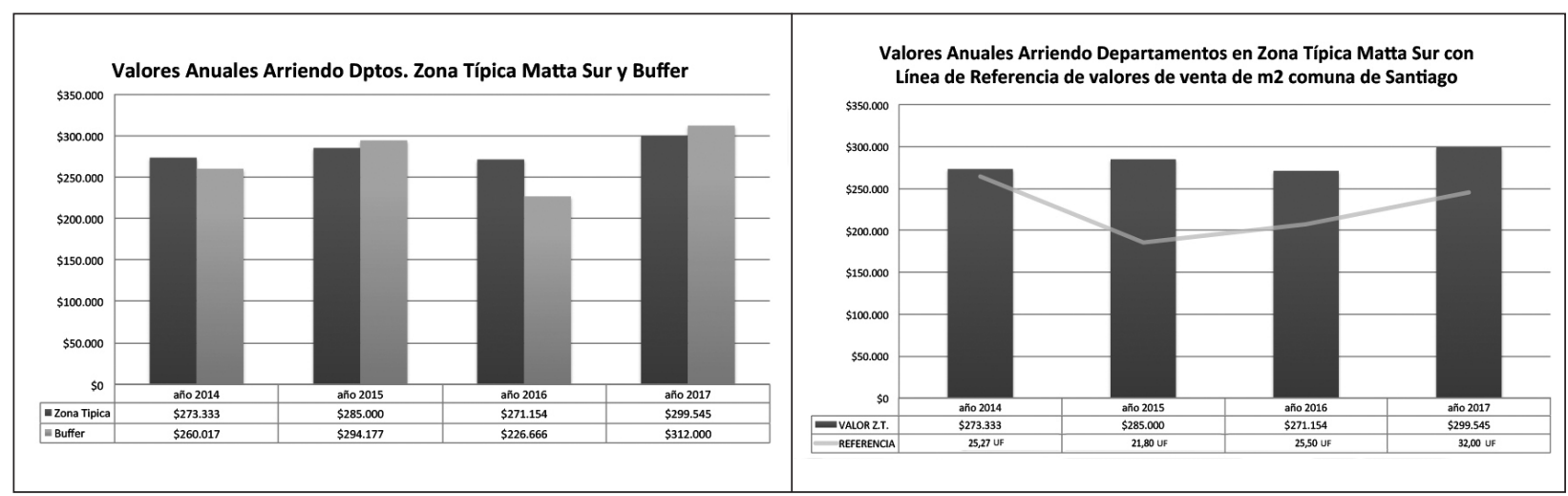

Fuente: elaboración propia.

curva de valores de suelo de $\mathrm{m}^{2}$ en la comuna de Santiago, la zona típica de Yungay tiene un comportamiento similar al alza general de la comuna (Figura 5).

Para el caso de Matta Sur (Figura 6), declarado zona patrimonial en 2016, el promedio precio oferta de arriendos presenta una baja el año de la declaratoria. Este fenómeno es coincidente con el comportamiento de las zonas típicas de Yungay, Villa Frei y Empart, que el año que han sido declaradas presentan una baja o un estancamiento de los precios de oferta para luego presentar un alza importante en el ciclo pos declaratoria. Esto puede significar una reacción del mercado inmobiliario movido por la incertidumbre del efecto de la declaratoria, que marcaría el inicio del ciclo especulativo posterior, pero no hay datos suficientes que permitan explicar este fenómeno. Respecto del promedio de precio arriendos del área buffer, se concluye un comportamiento similar al polígono declarado, tanto al alza como a la baja, lo que permite afirmar un cierto contagio de la zona colindante respecto de los ciclos presentes en el área protegida. Al superponer la tendencia de la curva de valores de suelo $\mathrm{m}^{2}$ comuna de Santiago (Figura 6), la zona típica de Matta Sur tiene un comportamiento distinto respecto de la contracción de 2015, bajando sus precios de oferta promedio al año siguiente. De mismo modo el alza de la curva del valor de $\mathrm{m}^{2}$ 
comunal iniciada el 2016, es seguida un año después en el sector.

De todas formas, no se aprecia una tendencia general a la baja de los precios de arriendo en la zona, por el contrario, la tendencia al alza se inicia con cierta aceleración, desde 2017. La incidencia del proceso de patrimonialización es hipotéticamente probable, en cuanto la tendencia no sigue la curva de valores de $\mathrm{m}^{2}$ comunal, aunque el comportamiento similar de precios del buffer hace muy complejo aislar la patrimonialización como una causa determinante del comportamiento de precios.

\section{Percepción respecto del comportamiento del precio de arriendo y venta de viviendas por parte de los vecinos}

Como se ha demostrado, hay un incremento de los precios de venta y arriendo de viviendas en los barrios estudiados. Cuando se les consulta a los vecinos si estas alzas son atribuibles a las declaratorias patrimoniales, los resultados indican que existe un porcentaje significativo de población residente en estos barrios tradicionales que correlaciona la patrimonialización con el aumento de plusvalía en el sector.
Solo el 18, 1\% de los residentes de total de zonas típicas estudiadas considera que, frente al alza de precios de vivienda y arriendo en el barrio, la declaración patrimonial no incide de ninguna forma. Mientras que un significativo $72,4 \%$, considera que si influye. Destaca un 62\% que declara que la zona típica impacta mucho sobre los valores de las propiedades.

En el caso del barrio Yungay, el porcentaje de residentes que considera que la declaración patrimonial no incide de ninguna forma frente al alza de precios de venta y arriendo es bastante bajo respecto del promedio del total de zonas estudiadas, alcanzando solo el 10\%. Es muy relevante el 72,7\% que declara que el alza de precios tiene mucha relación con la patrimonialización del barrio. Este caso es interesante, ya que, a diferencia de los barrios ñuñoínos, que han recibido la noticia de la llegada de estaciones de metro en o muy próximas a la zona; en Yungay, la variable de patrimonialización puede aislarse, en teoría, más respecto del alza de precios de los inmuebles, ya que no hay proceso de modernización que impacte tan claramente sobre la plusvalía del sector. Cabe señalar que esta zona típica es la de mayor data de las estudiadas, fue declarada el año 2009, por tanto, los residentes pueden tener una visión de más largo plazo respecto de la plusvalía del sector.

Un porcentaje significativamente importante de residentes de Villa Frei (75\%) afirma que la 


\section{FIGURA 7. FOTOGRAFÍA VISTA DE LAS TORRES DE VILLA FREI DESDE UNO DE SUS PUENTES REMOZADOS RECIENTEMENTE.}

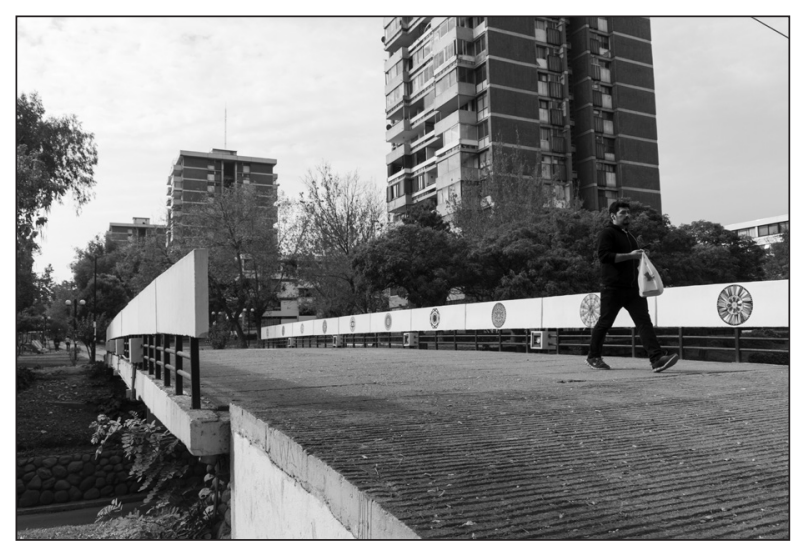

Fuente: proyecto Fondecyt iniciación 11150218

declaratoria ha incidido en el aumento de precios (65\% piensa que mucho). Sin embargo, hay un importante número de residentes, aunque menor (20\%) que cree que no ha habido influencia de la patrimonialización en las alzas de precios de venta y arriendo. Esto es atribuible al impacto de la nueva línea de metro que cruza la comuna, con una estación en el acceso del conjunto y al alza general de precios comunal (Figura 7).

Los activistas patrimoniales de Nuñoa coinciden en que la declaratoria no ha deteriorado el sector, por el contario, ha valorizado económicamente los inmuebles, de la mano del alza general de precios en la comuna.

\footnotetext{
"Tuvimos dos grandes situaciones que pasaron. Casi toda Ñuñoa, tuvo una subida de plusvalía grande. Yo me compré mi departamento, a un precio determinado y en 10 años se ha triplicado. Tiene que ver también con que estos barrios, tienen todo un encanto y esto tiene un plus, el hecho de que haya sido declarado zona típica". Entrevista profesional equipo técnico Empart (marzo, 2016).
}

Otro testimonio de una dirigente del mismo conjunto reafirma la percepción:

"La gente después empezó a sentir orgullo de ser zona típica. Se revalorizó muchísimo y los valores son un poco escandalosos. Yo compré mi departamento hace 20 años, en 16 millones, y hoy (2016) los más baratos los están vendiendo en 111 millones". Entrevista dirigenta Empart (marzo, 2016.

Inclusive, para el caso de Empart se señala que el impacto respecto de la declaratoria se da no solo en la plusvalía generada al interior de la zona, sino que también en los bordes, donde el capital inmobiliario captura las externalidades positivas del área patrimonial (Figura 8):

"En el borde poniente tenemos cuatro o cinco torres que se construyeron en un período de cinco años, que generan conos de sombra. Yo creo que las inmobiliarias han usufructuado". Entrevista profesional equipo técnico Empart (marzo, 2016). 
Por su parte, para el caso de Villa Olímpica, un importante $28,6 \%$ de los residentes considera que la declaratoria no influye en el alza de precios, la más alta respecto de todos los casos estudiados. Mientras que un 50\% considera que, si influye mucho, el más bajo de las zonas estudiadas. Esto se puede explicar por al menos dos razones: la declaratoria es muy reciente, septiembre de 2016. La encuesta se realizó a menos de un año de la declaratoria, lo que podría explicar esta sensación de un leve incremento. Otro aspecto es el influjo de nueva estación de metro que llega al borde de la villa.

En Matta Sur, por tratarse de una declaratoria reciente (enero de 2016), es posible que la percepción positiva del impacto en el alza de precios no sea tan significativa como en los otros casos, llegando al 63\%; en el caso de quienes piensan que no influye la cifra se eleva a poco más del $21 \%$.

Ahora bien, en términos generales, se concluye que, para la percepción de los habitantes de las zonas recientemente declaradas, el proceso de patrimonialización es un factor relevante respecto del alza general de los precios de venta y arriendo de inmuebles al interior del área protegida. Algunos relatos plantean una valorización general del área, incluyéndolos los paños colindantes a los polígonos de declaratorias (Figura 9).

\section{Arribo de nuevos habitantes con mayor poder adquisitivo}

Junto con esta percepción general de una valoración de la zona y un alza de los precios de venta y arriendo de inmuebles, se reconoce que muchos vecinos advierten que el barrio se ha vuelto atractivo para un perfil de jóvenes familias y profesionales. Algunos activistas reconocen que el hecho de que el barrio sea declarado patrimonio, lo hace atractivo para un tipo de residentes que valora los atributos de la escala barrial, el valor histórico y arquitectónico y la amplitud de los departamentos:

"En el aviso de venta le ponen: 'zona típica'. Porque además llegan los jóvenes y buscan espacios como estos. Fui a ver un departamento para mi sobrino y la persona que me lo mostró, cuando terminó de hablar me dijo: 'Y le recuerdo que estamos en una zona típica'. Entrevista dirigenta Empart (marzo, 2016).

Para esta percepción la declaratoria patrimonial se vuelve un elemento de distinción, que, dada sus escases, se trasunta en un aumento de los valores de venta. 
FIGURA 8. FOTOGRAFÍA DESARROLLO INMOBILIARIO EN ALTURA EN ÁREA COLINDANTE A ZONA TÍPICA EMPART.

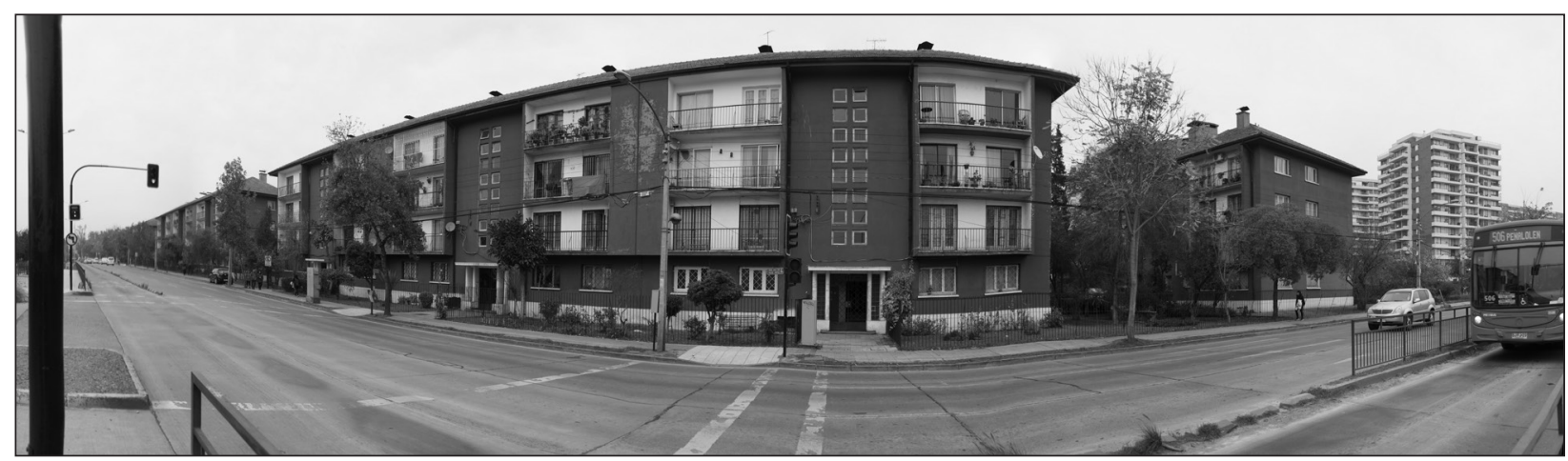

Fuente: proyecto Fondecyt Iniciación 11150218

FIGURA 9. FOTOGRAFÍA ESCALA BARRIO MATTA SUR Y DENSIFICACIÓN EN ALTURA COLINDANTE.

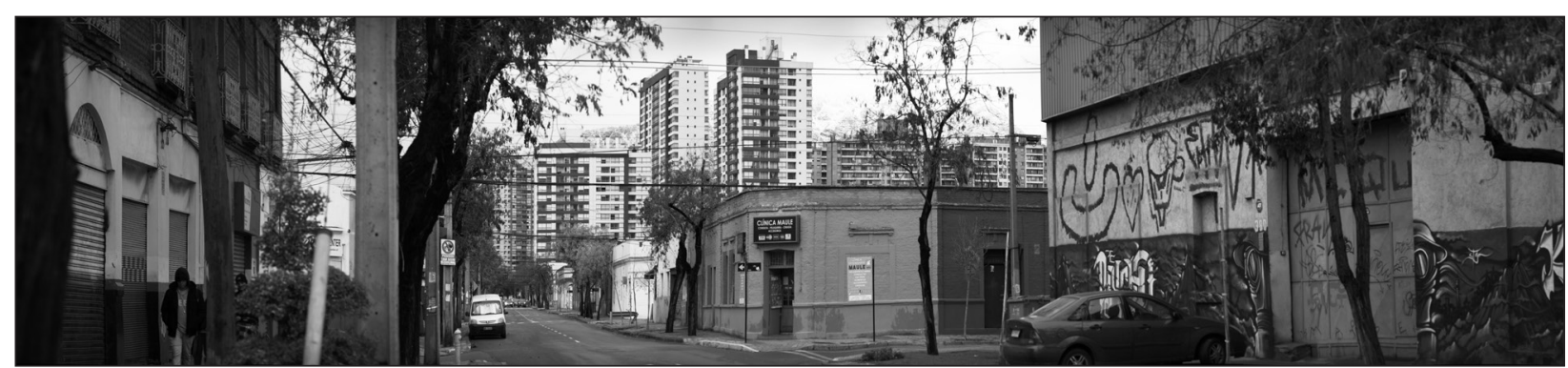

Fuente: proyecto Fondecyt Iniciación 11150218. 
Ahora bien, al cruzar datos respecto del tiempo de permanencia y el ingreso familiar en Villa Olímpica, se puede apreciar que los niveles superiores de ingreso están asociados a permanencias más cortas -menos de cinco años-. Los datos confirman esta tendencia cuando se cruza el tiempo de permanencia en la vivienda con el valor de arriendo, los valores más altos se concentran en los residentes con menos tiempo de permanencia.

En Yungay se reconoce la existencia de un imaginario que ha permitido que se construya y consolide la idea de un barrio cultural -"La Peluquería Francesa, el bar Serena, el Centro Cultural Manuel Rojas. Hay una renovación de la gente del sector que apoya la zona típica, hay todo un circuito". Entrevista vecino barrio Yungay (septiembre, 2016).

Esta mixtura entre antiguos residentes que dan memoria al lugar y un nuevo grupo de habitantes que valoriza y difunde los elementos identitarios que construyen este relato ha permitido transformar al barrio en un referente cultural para todo el país. Este reconocimiento se expresa en la llegada de un nuevo perfil de residentes. De hecho, al cruzar ingresos por permanencia un número significativo de hogares que perciben un ingreso superior a los $\mathrm{M} \$ 2.000$ reside hace menos de cinco años y el total de ellos hace menos de 10 (Figura 10). Ahora bien, cabe destacar que una característica predominante del barrio es su componente pluriclasista, lo que se nota con la llegada de residentes de ingresos bajos y de arriendos y subarriendos económicos también en los últimos cinco años. Ahora bien, esta población de nuevos arrendatarios corresponde en su gran mayoría inmigrantes trasnacionales, que viven en condiciones de pobreza y segregación social, lo que para algunos autores españoles y latinoamericanos es un indicador de nuestra particular geografía de la gentrificación (Janoschka et al., 2014).

En el caso de Matta Sur, se percibe un aumento de nuevos residentes, con interese culturales y patrimoniales: "Ya no es el barrio de hace una década: un barrio viejo, sino que llegan personas jóvenes, artistas y hacen su propuesta de atelier, centros culturales y ellos tratan de vincularlo a la defensa del patrimonio". Entrevista vecino Matta Sur (agosto, 2016).

La composición social que caracteriza los barrios es heterogénea, siendo Yungay el barrio con mayor mixtura social, importantes sectores vulnerables se aprecian en Matta Sur, mientras que en las villas de Ñuñoa se nota un componente mayoritario de clase media. Sin embargo, en todos los barrios se puede apreciar la llegada reciente de nuevos residentes con ingresos iguales o superiores a la población original. Respecto a la tenencia se aprecia un número similar de arrendatarios y propietarios con excepción del barrio Yungay, donde el arriendo supera con creces a los propietarios. En cuanto a la permanencia el barrio Yungay marca una gran 
FIGURA 10. FOTOGRAFÍA DE UN LOFT EN EL BARRIO YUNGAY.

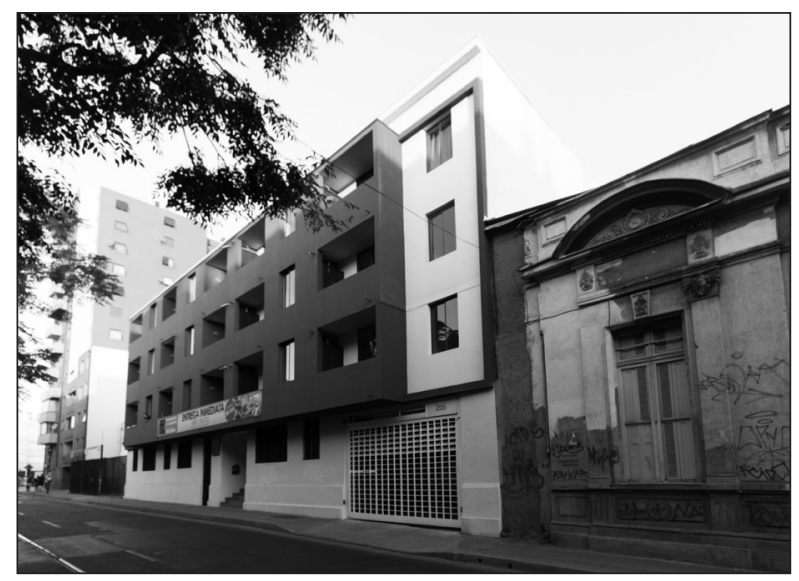

Fuente: proyecto Fondecyt Iniciación 11150218

rotación habitacional, asociada al subarriendo y la inmigración mientras que Matta Sur y Villa Olímpica tienen un importante porcentaje de población que reside más de 20 años. Yungay y Matta Sur dan cuenta de una importante presencia de población migrante, y se constituyen como barrios multiculturales. En cuanto al capital social, se aprecia un número significativo de habitantes que participan en alguna organización del sector. De ellos una mitad lo hace en organizaciones tradicionales, como Juntas de Vecinos y otro tanto en organizaciones sociales emergentes, de interés ambiental o cultural.

\section{FIGURA 11. FOTOGRAFÍA DE LA NUEVA OFERTA GASTRONÓMICA Y CULTURAL EN EL BARRIO YUNGAY.}

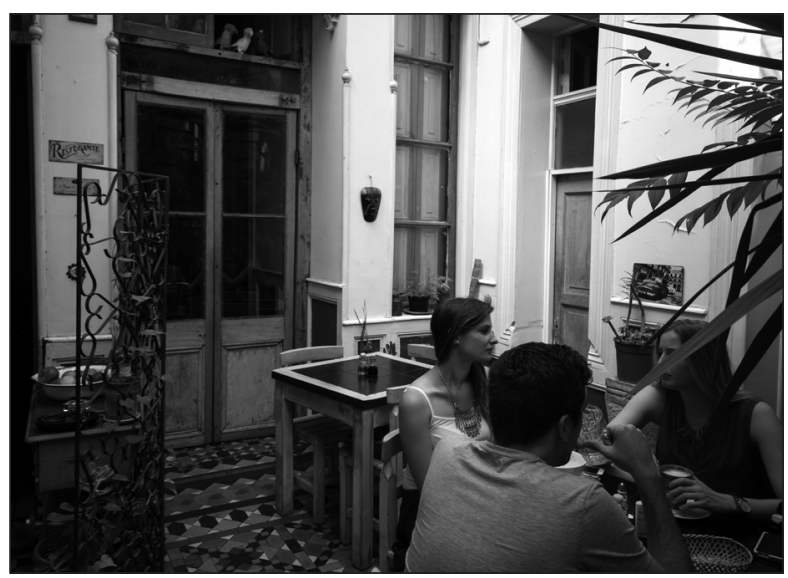

Fuente: proyecto Fondecyt Iniciación 11150218.

\section{Presencia de nuevos programas culturales y de ocio}

También se reconoce que la llegada de nuevos programas a algunos de estos barrios, en particular a Yungay, como restaurantes y centros culturales que han renovado la identidad del barrio y potenciado su veta cultural: "Le están dando otro enfoque al barrio. El barrio está de moda". Entrevista vecino barrio Yungay (septiembre, 2016). 
Los vecinos tradicionales que han decidido quedarse en el barrio optan por cambiar el uso de sus viviendas a comercio. Estos nuevos equipamientos pueden, para los líderes del barrio, generar procesos gentrificadores:

\footnotetext{
"Se renueva comercio, hoteles, por ejemplo, el restaurant La Gárgola. Eso después de la zona típica. El recientemente llegado Centro Cultural Nave, rescata la fachada, instala un programa raro para el barrio, instala una suerte de hotel-teatro. Pero también es un espacio cerrado. Puede ser entendido como espacio de gentrificación. No es para migrantes. Es para alguien que cultiva la danza, y que está ahí por algún tiempo. Nave se relacionó, desde que empezó a funcionar, con las organizaciones vecinales, ha prestado su infraestructura para actividad cultural. Nave ha colaborado con la consolidación del tejido actual, entonces gentrifica, pero no le da la espalda al proceso barrial." Entrevista activista barrio Yungay (octubre, 2016)
}

Respecto a la naturaleza de los nuevos programas y a la capacidad de las organizaciones comunitarias de negociar y disputar el territorio simbólico con los nuevos actores comerciales, se percibe a la gentrificación como un fenómeno que determinará el futuro barrial (Figura 11):

"Lo que veo son hoteles boutique. De hecho, la vocería de campaña de la ex alcaldesa en la última elección fue en un hotel boutique. Veo más comercio gentrificado, cercano a Nave, que organizaciones más comunitarias como el Centro Cultural Manuel Rojas. Lo social-comunitario es costoso a nivel de la gente que lo está desarrollando. A diferencia de Manuel Rojas, hay otras instituciones que son más fuertes y que son capaces de durar, como la "Escuela Fermín Vivaceta", la Junta de Vecinos," o "Vecinos por el Barrio Yungay" Entrevista Activista Barrio Yungay (septiembre, 2016).

Para los vecinos de Matta Sur la gentrificación es un tema que se debe afrontar en el futuro, ya que el reconocimiento como barrio histórico puede generar un proceso de abandono y de reciclaje de re-edificación para sectores sociales con más poder adquisitivo.

"El barrio hay que defenderlo, fue una gran lucha lograr la declaración de zona típica. Pero, a través de recuperar el patrimonio se puede intentar que el barrio se gentrifique y atraiga al capital inmobiliario. Eso provoca la obsolescencia urbana programada de parte del municipio y las inmobiliarias (...) Hay que estar atento, porque a veces se puede tergiversar el uso de los conceptos patrimoniales ciudadanos para favorecer la gentrificación bajo fuego de las inmobiliarias". Entrevista vecina Matta Sur (agosto, 2016). 
TABLA 1. SÍNTESIS DE INDICADORES DE GENTRIFICACIÓN POR ZONA TÍPICA.

\begin{tabular}{|c|c|c|c|c|c|}
\hline \multirow[t]{2}{*}{ Indicadores de gentrificacion } & \multicolumn{5}{|l|}{ Barrios } \\
\hline & Matta Sur & Yungay & Villa Frei & EMPART & $\begin{array}{l}\text { Villa } \\
\text { Olímpica }\end{array}$ \\
\hline $\begin{array}{l}\text { Comportamiento al alza del mercado } \\
\text { habitacional }\end{array}$ & sí & sí & sí & sí & sí \\
\hline $\begin{array}{l}\text { Arribo de residentes con mayor poder } \\
\text { adquisitivo }\end{array}$ & NO & sí & sí & sí & sí \\
\hline $\begin{array}{l}\text { Presencia de nuevos programas culturales y } \\
\text { de ocio }\end{array}$ & NO & sí & NO & NO & NO \\
\hline Desplazamiento de población vulnerable & NO & NO & NO & NO & NO \\
\hline
\end{tabular}

Fuente: elaboración propia.

\section{Desplazamiento de población vulnerable}

En el caso de las zonas típicas ñuñoínas, si bien no se reconocen fenómenos masivos de expulsión de habitantes de bajos ingresos por el aumento de renta y costo de vida, sí hay temor de que eso sea una posibilidad futura:

"Ha habido cuestionamientos de las organizaciones con respecto a la efectividad de ser patrimonio dentro del barrio. Sobre todo, las organizaciones más jóvenes. Hay temor de que se vuelva un barrio de moda, que se expulse al vecino". Entrevista dirigenta Villa Olímpica (julio, 2016).
Para el caso de Matta Sur, se reconoce un aumento del precio de las viviendas y un proceso de expulsión de población pobre y de inmigrantes:

"Los precios de las casas han subido harto, hoy una casa cuesta como 120 millones. Creo que esto es bueno para los propietarios de las casas, pero súper malo para los arrendatarios, no tenemos datos exactos, pero hemos visto algunos vecinos que arrendaban que han tenido que irse porque les subieron harto el arriendo. También los migrantes vemos que están siendo desplazados, ya que sabemos que hay varias casas que las subarriendan por piezas y viven inmigrantes haitianos, colombianos y peruanos". Entrevista dirigenta Matta Sur (agosto, 2016). 
Es posible que el alza de precios impacte más sobre los arrendatarios, ya que un $11 \%$ más de arrendatarios que de propietarios reconoce un alza importante de precios de arriendo.

\section{Conclusiones}

El presente artículo buscó reconocer si sectores declarados como zonas típicas, han sufrido procesos de deterioro o valorización. En cuanto a la metodología se desarrolló una breve sistematización bibliográfica del concepto de gentrificación. Del mismo modo, se realizó un análisis de los resultados de una encuesta a una muestra de residentes de cinco zonas típicas y un análisis de percepción a través de relatos de vecinos y activistas patrimoniales de las áreas estudiadas. Por último, se analizó el comportamiento de los precios de la oferta de inmuebles al interior y en el borde de los barrios estudiados, con el fin de reconocer un posible proceso de gentrificación.

Respecto a la visión de los residentes de las zonas típicas hay una opinión clara en cuanto a que la declaratoria patrimonial no ha generado deterioro en los barrios. Por el contrario, la mayoría reconoce cambios positivos en los barrios después de la declaratoria. Del mismo modo, consideran que la declaratoria ha incidido en el alza de precios de venta y arriendo de inmuebles en las zonas. La composición social que caracteriza los barrios es heterogénea, siendo Yungay el barrio con mayor mixtura social. Importantes sectores vulnerables se aprecian en Matta Sur, mientras que en las villas de Nuñoa se nota un componente mayoritario de clase media. Sin embargo, en todos los barrios se puede apreciar la llegada reciente de nuevos residentes con ingresos iguales o superiores a la población original. Respecto a la tenencia se aprecia un número similar de arrendatarios y propietarios con excepción del barrio Yungay, donde el arriendo supera con creces a los propietarios. En cuanto a la permanencia el barrio Yungay marca una gran rotación habitacional, asociada al arriendo y la inmigración mientras que Matta Sur y Villa Olímpica tienen un importante porcentaje de población que reside más de 20 años. Yungay y Matta Sur dan cuenta de una importante presencia de población migrante, y se constituyen como barrios multiculturales. En cuanto al capital social se aprecia un número significativo de habitantes que participan en alguna organización del sector.

Respecto a si existen indicadores que den cuenta del proceso de gentrificación en los barrios, se puede mencionar que: existe un aumento significativo de los valores de venta y arriendo de inmuebles en las zonas estudiadas, tras las declaratorias patrimoniales, sin embargo, no es posible con certeza argumentar que esas alzas responden a la patrimonialización del sector, ya que existen otras 
variables incidentes. Desde el estudio de la oferta inmobiliaria resulta complejo aislar la variable de patrimonialización de otros factores coadyuvantes a la valorización, sin embrago, en los datos arrojados respecto de la percepción de los habitantes si resulta ser un elemento reconocido como significativo. También se reconoce el arribo no masivo de un nuevo perfil de residente, que llega atraído por la oferta cultural de ocio y la escala barrial de los sectores. No se aprecia una expulsión masiva de residentes de escasos recursos, aunque existen casos puntuales en Matta Sur y Yungay, lo que genera el temor, entre los activistas, a que el fenómeno se masifique. Respecto a cambio de programación y nuevos equipamientos de ocio, cultura y gastronomía se aprecian con claridad solo en zonas definidas del barrio Yungay. En suma, no se aprecia un patrón clásico de gentrificación, sin embargo, hay indicadores de que se está en presencia de un proceso particular de revitalización, que puede tener efectos aún no percibidos en cuanto a la recomposición social de los sectores. En este sentido se puede señalar, en concordancia con otros estudios de la región, que el proceso de revalorización en estos barrios históricos no corresponde al patrón clásico de gentrificación y que se caracteriza por la ausencia de procesos significativos de desplazamiento de población. Del mismo modo, en el caso del barrio Yungay, se aprecia, al igual que en otros casos latinoamericanos, la coexistencia de estratos sociales altos y bajos y la co-presencia de oferta de servicios para sectores de altos ingresos y de vocación turística, junto con servicios y comercio tradicionales y de proximidad.

\section{Referencias bibliográficas}

Brenner, N., Peck, J., y Theodore, N. (2009). Urbanismo neoliberal: la ciudad y el imperio de los mercados. Temas Sociales, 66, 1-11.

Contreras, Y. (2016). Los nuevos habitantes del centro de Santiago. Santiago: Universitaria.

Delgadillo, V. (2015). Patrimonio urbano, turismo y gentrificación. En V. Delgadillo, I. Díaz y L. Salinas (Coords.), Perspectivas del estudio de la gentrificación en México y América Latina. México: UNAM.

Deutsche, R. (1996). Evictions. Art and spatial politics. Cambridge, Massachusetts: MIT Press.

Deutsche, R. y Gendel, C. (2015). El bello arte de la gentrificación. En Observatorio Metropolitano de Madrid (Ed.), El mercado contra la ciudad. Sobre globalización, gentrificación y politicas urbanas (pp. 27-52). Madrid: Traficantes de Sueños.

Ducci, M.E. (2004). Las batallas urbanas de principios del tercer milenio. En Santiago de Chile en la era de la globalización. Santiago: Sur.

Duering, E., González, C., e Hiernaux, D. (2016). Nuevas políticas urbanas, gentrificación y resistencia: movimientos sociales incipientes en Querétaro. En F. Carrión y J. Erazo (Coords.), El derecho a la 
ciudad en América Latina. Visiones desde la politica (pp. 241-257). México: UNAM.

Dureau, F., Barbary, 0., y Lulle, T. (2007). Dinámicas metropolitanas de poblamiento y segregación. En Ciudades y sociedades en mutación. Lecturas cruzadas sobre Colombia, (pp. 161-236). Colombia: Universidad Externado de Colombia.

Florida, R. (2002). The rise of the creative class: and how it's transformation work, leisure, community, and everyday life. Nueva York: Basic Books.

Glass, R. (1964). London: Aspects of change. Londres: Mac Gibbon \& Clee.

Harvey, D. (2012). Ciudades rebeldes. Del derecho de la ciudad a la revolución urbana. España: Akal.

Hiernaux, D. y González, C.I. (2014) Turismo y gentrificación. Pistas teóricas sobre una articulación. Revista de Geografia Norte Grande, (58), 55-70. https:// doi.org/10.4067/S0718-34022014000200004

Inzulza, J. y Galleguillos, X. (2014) Latino-gentrificación y polarización: trasformaciones socioespaciales en barrios pericentrales y periféricos de Santiago, Chile. Revista de Geografía Norte Grande, (58), 135-159. https://doi.org/10.4067/ S0718-34022014000200008

Irarrázaval, A. (2017). Hacia una gestión sustentable del patrimonio arquitectónico chileno. Santiago: Cámara Chilena de la Construcción. Recuperado de http://www.cchc.cl/uploads/archivos/archivos/ Fundamenta_CChC_43.pdf
Janoschka, M., Sequera, J., y Salinas, L. (2014). Gentrificación en España y América Latina. Un diálogo crítico. Revista de Geografía Norte Grande, (58), 7-40. https://doi.org/10.4067/ S0718-34022014000200002

Jeri, T. (2015). Impacto de declaratorias de zonas típicas y pintorescas en el desarrollo del centro histórico. (Tesis de Magíster en Ciencias Sociales, Facultad de Ciencias Sociales, Universidad de Chile, Santiago). Recuperado de: http://repositorio.uchile.cl/ handle/2250/140828.

Lees, L., Slater, T., y Wyli, E. (2008). Gentrification. New York: Routledge.

López, E., Gasic, I., y Meza, D. (2012). Urbanismo pro-empresarial en Chile: políticas y planificación de la producción residencial en altura en el pericentro del Gran Santiago. Revista INVI, 27(76), 75-114. https://doi.org/10.4067/ S0718-83582012000300003

Navarrete, D. (2017). Turismo gentrificador en ciudades patrimoniales. Exclusión y transformaciones urbano-arquitectónicas del patrimonio en Guanajuato, México. Revista INVI, 32(89), 61-83. https:// doi.org/10.4067/S0718-83582017000100061

Pacione, M. (1990). Urban problems. An applied urban analysis. Londres: Routledge.

Rojas, M. (2015). Dialéctica del patrimonio: modernizaciones y cultura activa en disputa. México: Del Lirio.

Slater, T. (2015). La expulsión de las perspectivas críticas en a investigación sobre gentrificación. En Observatorio Metropolitano de Madrid (Ed.), El 
mercado contra la ciudad. Sobre globalización, gentrificación y politicas urbanas (pp. 107-156). Madrid: Traficantes de Sueños.

Sabatini., F., Vásquez, H., Robles, S., y Rasse, A. (2010). Gentrificación sin expulsión, fuerzas de transformación de las ciudades latinoamericanas: datos e interpretación para Santiago. En Tendencias de la segregación en las principales ciudades chilenas: análisis censal 1982-2002 (pp. 165-184). Santiago: PUC-INE.

Sobarzo, M. (2009). Gubernamentalidad patrimonial. En P. Aravena y M. Sobarzo, Valparaíso. Patrimonio, mercado y gobierno (pp. 37-59). Concepción: Escaparate.

Valencia, M. (2016). Proyecto, obra, comunidad. Arquitectura habitacional moderna en Santiago de Chile. Santiago: LOM.

Valencia, M. (2017). Tensiones entre procesos de patrimonialización y modernización neoliberal. El caso de los paisajes culturales modernos: Conjuntos habitacionales y barrios obreros en América Latina en el siglo XX. Revista de Urbanismo, (36). https://doi.org/10.5354/0717-5051.2017.45198

Vergara, C. y Casells, A. (2016). Políticas estatales y transformación urbana. ¿Hacia un proceso de gentrificación en Valparaíso Chile? EURE, 42(126), 23-144. https://doi.org/10.4067/ S0250-71612016000200006

Smith, N. (2012). La nueva frontera urbana. Ciudad revanchista y gentrificación. Madrid: Traficantes de sueños.
Smith, N. (2015) Nuevo globalismo y nuevo urbanismo. La gentrificación como estrategia urbana global. En El mercado contra la ciudad. Sobre globalización, gentrificación y politicas urbanas (pp. 245-270). Madrid: Traficantes de Sueños.

Trivelli, P. (2017). Boletín trimestral de precios de suelo.

Urbina, A.d. (2015). Deterioro del patrimonio urbano y proceso de gentrificación. Un estudio del centro histórico de Bogotá, Colombia. En P. Torres y A. Cedeño (Coords.), Ecourbanismo y habitabilidad regional. Contribuciones de América Latina (pp. 221-235). México: Universidad Autónoma Metropolitana.

Zibechi, R. (2015) Latiendo resistencia. Mundos nuevos y guerras del despojo. Santiago: Quimantú. 